\title{
Expectancy in humans in multisecond peak-interval timing with gaps
}

\author{
Claudette Fortin \\ Université Laval, Québec City, Québec, Canada \\ Steve Fairhurst and Chara Malapani \\ Columbia University, New York, New York \\ and New York State Psychiatric Institute, New York, New York \\ Caroline Morin \\ University of Warwick, Coventry, England \\ JAMES TOWEY \\ Columbia University, New York, New York \\ and New York State Psychiatric Institute, New York, New York \\ AND \\ WARREN H. MECK \\ Duke University, Durham, North Carolina
}

\begin{abstract}
In two experiments, the peak-interval procedure was used with humans to test effects related to gaps in multisecond timing. In Experiment 1, peak times of response distributions were shorter when the gap occurred later during the encoding of the criterion time to be reproduced, suggesting that gap expectancy shortened perceived durations. Peak times were also positively related to objective target durations. Spreads of response distributions were generally related to estimated durations. In Experiment 2, peak times were shortest when gaps were expected but did not occur, confirming that the shortening effect of gap expectancy is independent of the gap occurrence. High positive start-stop correlations and moderate positive peak-time-spread correlations showed strong memory variability, whereas low and negative start-spread correlations suggest small response-threshold variability. Correlations seemed not to be influenced by expectancy. Overall, the peak-interval procedure with gaps provided relevant information on similarities and differences in timing in humans and other animals.
\end{abstract}

Estimating time is a fundamental ability involved in numerous everyday activities such as using natural pauses in conversation or social interactions, practicing sports, playing musical instruments, or moving and pausing in a changing environment (Buhusi \& Meck, 2005; Gibbon, Malapani, Dale, \& Gallistel, 1997). Various sources of interference in human time estimation have been identified when concurrent tasks requiring attention and memory were performed with timing (Brown, 1997). The role of expectancy was specifically analyzed in recent studies, showing that a time interval was judged shorter when a stimulus or an interruption in timing was expected during the interval (Casini \& Macar, 1997; Macar, 2002; Tremblay \& Fortin, 2003).

Studies with animals, using a peak-interval (PI) procedure with gaps, suggest that mechanisms related to memory and attention may contribute to performance in animal timing (e.g., Buhusi \& Meck, 2000, 2002, 2006a, 2006b, 2007; Buhusi, Perera, \& Meck, 2005; Buhusi, Sasaki, \& Meck, 2002; Cabeza de Vaca, Brown, \& Hemmes, 1994). Gaps were also used in a time reproduction task with humans. In this task, participants are first trained to reproduce a target duration (e.g., $2 \mathrm{sec}$ ), and a stimulus (e.g., a tone) is presented during its reproduction. Then, in experimental trials, a gap in stimulus presentation defines a brief period during which timing must be interrupted. Gap location and duration are varied. In this task, humans consistently end the interval reproduction later when the gap occurs later, and the length of reproduced intervals appears to be proportional to the duration of gap expectancy. Longest intervals are reproduced when a gap is expected throughout the interval reproduction but never occurs (Fortin \& Massé, 2000), which confirms that reproduced intervals are lengthened by gap expectancy. The objective of the present study was to examine whether such effects may be observed in humans, using a PI procedure with 
gaps, which provides information unavailable with a time reproduction method.

In duration reproduction, a single keypress terminates the interval. The time between the beginning and the end of the interval is an estimate of the remembered target duration. It is assumed that during the interval, the current estimate of the time elapsed since the beginning is compared with the memory representation of the target duration, so that the reproduction is terminated when the two values correspond. When a gap is expected, longer reproduced intervals result from time-sharing between estimating time, represented as accumulating temporal information, and monitoring for the gap signal, which requires attention. This perturbs the accumulation process, which also needs attention to operate. The amount of temporal information accumulated when a gap is expected will therefore be lower, so that more time will be needed to reach the subjective target duration - hence, longer reproduced intervals.

This interpretation relies on an accumulation framework commonly used to interpret the effects of distraction on timing (Brown, 1997; Buhusi \& Meck, 2006a, 2006b; Zakay, 2000; Zakay \& Block, 1996). It is also the basis of the scalar expectancy theory (SET; Gibbon, 1977; Gibbon \& Church, 1990; Gibbon, Church, \& Meck, 1984), in the context of which responding in the PI procedure has been extensively analyzed. Three processing stages are distinguished in SET: a clock stage, a memory stage, and a decision stage. At the clock stage, a Poisson pacemaker emits temporal indices (pulses), and an accumulator integrates pulses, if permitted by an attention-controlled switch. The accumulator content may be transferred in working memory. At the decision stage, the current accumulated time is compared with a value sampled from reference memory, and if the discrepancy between the two values is small enough, according to a given threshold, the interval is ended.

The time-sharing interpretation places the source of temporal distortion caused by gap expectancy at the clock level. Because attention is shared between the accumulating of pulses and monitoring for the occurrence of the gap signal, the rate of accumulation is reduced, leading to longer reproduced intervals in time production (Fortin, 2003). This conclusion is based on a single response in a given trial - that is, the keypress ending the temporal reproduction. In contrast, in the PI procedure, multiple responses are required on each trial. In a PI task with humans, for example, participants were exposed to a visual stimulus presented for a given time interval (e.g., $8 \mathrm{sec}$ ); this was the criterion time to reproduce in the testing phase of the experiment (Rakitin et al., 1998). In the testing phase, the visual stimulus appeared again but did not automatically end after the criterion time. Participants were asked to center their responses on the criterion time and to produce (at least four) responses, so that a response should be placed at the target duration. Two decisions must be made in this task: one to start responding, and one to stop responding. Two response times related to these decisions are recorded: the start time (the time between the beginning of stimulus presentation and the first response produced by the participant) and the stop time (the time between the beginning of tone presentation and the last response). The arithmetic mean of the start and stop values is the middle time, also called peak time, which is taken as an index of the remembered target duration in a given trial. The difference between the stop and start times represents the spread of response distribution, considered an index of variability in a trial. These measures provide information not only on the memory representation of the criterion time, as in the duration production method, but also on its variability in a current trial.

Using correlations between various measures in the PI procedure permits a trial-by-trial analysis that may be diagnostic of underlying sources of variance (Gibbon \& Church, 1990). The rationale is based on the SET assumptions. Start and stop times are determined by the reference memory and by a comparison process within SET. When a participant times a stimulus in a trial of the PI procedure, from the beginning of the stimulus elapsed time is continuously compared with a representation of the criterion or target time sampled from a distribution of clock readings stored in reference memory. The difference between the current time or clock reading and the target time representation dwindles as time elapses, and the start time will correspond to the time when the discrepancy between the current perceived time and the sample from reference memory reaches a given response threshold - that is, the participant considers the time "close enough" to the target to start responding. As time goes by, there will be a point of perfect correspondence between the current time and the sample taken from reference memory: the point at which the discrepancy value is zero. The discrepancy value will then increase until the threshold is met again; this corresponds to the stop time. The start and stop times thus represent two transition points centered on the target time. The start time represents a point below which the current time is judged as being "too short" to correspond to the remembered criterion in reference memory, and the stop time represents a point above which the current time is judged as being "too long." Previous research has shown these response thresholds to be proportional to the target times (Gibbon et al., 1984; Rakitin et al., 1998). Memory variance results in variance in the target time at which the discrepancy value is zero, and in corresponding variability in the centering of the start and stop times from trial to trial. When the sampled target time is shorter in a given trial than in another trial, this results in an earlier start time and an earlier stop time. Furthermore, given the assumption that the variability in the target time representation is positively related to the target time value, the spread of responding will be proportional to the target time. Variance in start and stop times permits computing correlations between these times, as well as between the start time and spread of responding (see Gibbon \& Church, 1990, pp. 44-45).

No variability in the memory representation of the criterion time will result in a window of responding centered at the remembered duration across trials that varies only in spread. Conversely, if there is no variability in the threshold values used to start and stop responding, the spread 
will not vary from trial to trial but should still be proportional to the target time, and its centering will vary from trial to trial, because of variability in memory for the target time. Under the extreme conditions of no variability in either memory or threshold, correlations between trial-bytrial measures should be zero. Introducing variability in the memory for the target time only will produce positive correlations between start and stop times, between start time and spread, and between middle time and spread, as described in the preceding paragraph. Introducing variance in threshold only should result in negative start-stop correlation, negative start-spread correlation, and no correlation between middle time and spread (see Gibbon \& Church, 1990, pp. 46-47). When there is variance from both memory (or clock and memory) and threshold, correlations are determined by the relative contribution of both sources.

Results of a study using the PI procedure with humans showed that human performance presents qualitative properties generally similar to those observed with animals: mean response distributions centered on criterion times, symmetrical and scalar in their variability (e.g., Hinton \& Meck, 2004; Lustig \& Meck, 2005; Rakitin et al., 1998). This was confirmed with a different method, the start-stop procedure, which yields performance measures comparable to those obtained with the PI procedure (Hemmes, Brown, \& Kladopoulos, 2004; Kladopoulos, Brown, Hemmes, \& Cabeza de Vaca, 1998). With both procedures, trial-by-trial analyses showed more variability attributable to memory processes than variability due to threshold processes (Kladopoulos et al., 1998; Rakitin et al., 1998).
Although manipulating gaps in the PI procedure has been studied extensively in animal timing research (Buhusi, 2003), it has never been tested with humans. In the present study, this method permitted us to (1) verify whether the PI procedure will reveal effects of varying gap location in humans, (2) verify the effect of varying gap location on within-trial measures of temporal performance, and (3) examine the contributions of memory and decisional processes when gaps are expected.

In the following two experiments, the timing task was divided into two main phases: a first one in which participants encoded the duration of a tone (the Observe phase in the top panel of Figure 1), and a second one in which they reproduced this duration (the Produce phase in the top panel of Figure 1). In the Observe phase, a tone of 2.4, 3.2, or $4.0 \mathrm{sec}$ was presented to the participant, who was asked to encode the target duration defined by the tone. After a brief pause, the Produce phase started with a second tone presentation. Having estimated that its duration was close to the just-presented target interval, the participant started to press a key repeatedly until judging the target duration to be over. In trials with gaps, the tone presented in the $\mathrm{Ob}-$ serve phase was briefly interrupted during its presentation (Figure 1, bottom). Participants were asked to encode the total duration of the tone, ignoring the gap in its presentation. Participants had therefore to start estimating time at the beginning of the tone presentation, to interrupt timing during the gap, and to resume timing at the end of the gap until the end of the tone. Their task was then, in the Produce phase, to reproduce the total tone duration, without including the gap duration.
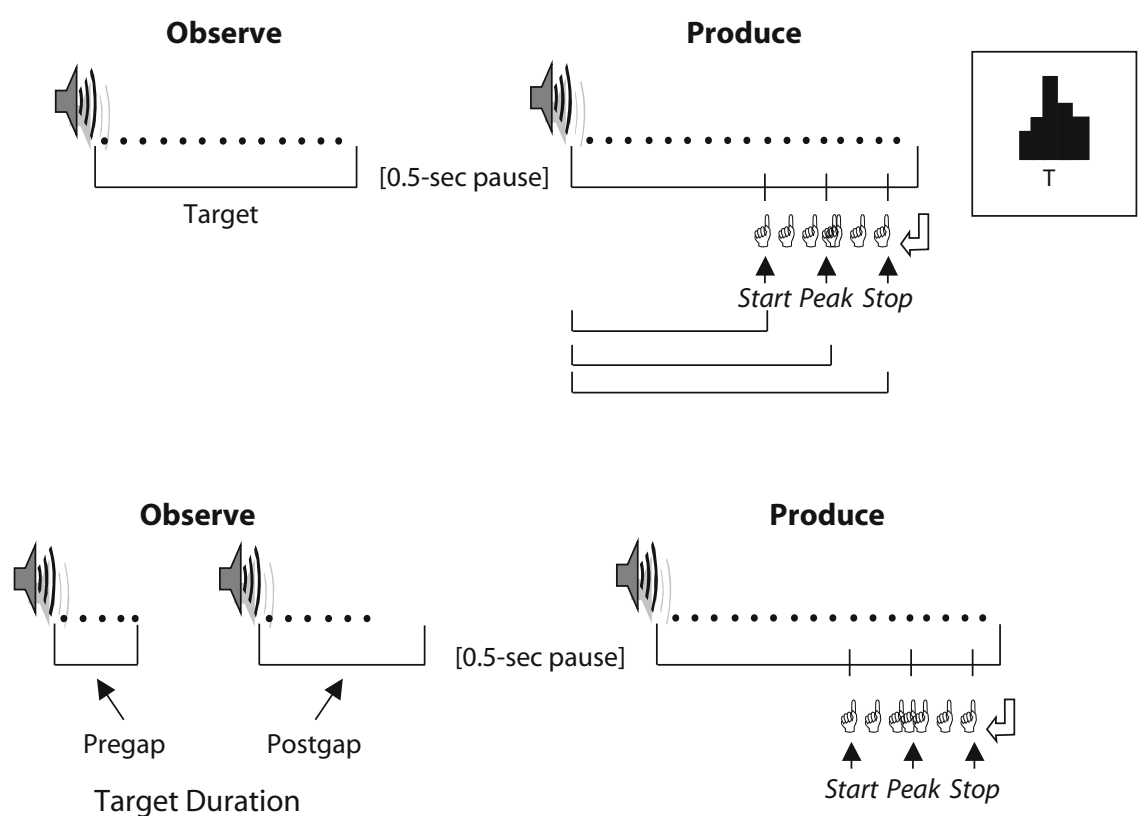

Figure 1. Schematic illustration of trials with no gap (top) and with a gap (bottom) in the peak-interval procedure. In the Observe phase, a tone is presented for some target duration. In the Produce phase, the duration is reproduced with multiple keypresses, which define a window of responding centered on the target duration. The trial is ended by pressing the Enter key. In some practice trials, a histogram feedback followed the end of trial, showing the response distribution and its position relative to the target duration. 
The target time interval presented in the Observe phase varied from trial to trial. In trials with gaps, location and duration of the gap also varied between trials. In Experiment 1, all trials in an experimental session included a gap. In Experiment 2, trials with no gap were mixed among trials with gaps in the experimental session, to test the effect of gap expectancy in the absence of gap occurrence.

Specific hypotheses were tested in the present study. A first hypothesis was that peak times should vary with varying gap location; more precisely, peak times should be shorter when the gap occurs later in target durations. This would support the interpretation of the gap location effect in terms of expectancy: Expecting a gap in the Observe phase of the PI task should shorten the perceived target duration, and the shortening should be proportional to the duration of the gap expectancy. Furthermore, according to Weber's law and the scalar property, variability should be lower when time estimates are shorter. A second hypothesis was, therefore, that if peak times are shorter with an increasing value of gap location (thus suggesting a shortening of perceived durations), variability, as measured by spread of responding in the PI procedure, should be lower. A third hypothesis concerns the effect of the gap duration. Lengthening the gap duration shortened produced intervals in some experiments (Fortin, Bédard, \& Champagne, 2005). This was interpreted as an effect of preparation during the gap; that is, in an experiment in which the gap varies in duration from trial to trial, participants have relatively more time, when it is longer, to prepare to resume timing afterward. Because of this higher level of readiness, participants resume timing more quickly when the gap is longer, thereby producing shorter intervals. In the PI procedure, resuming timing more quickly when the gap is longer in the Observe phase of the procedure should lead to longer perceived duration, and thus to longer peak times than when the gap is shorter. This would suggest that preparation can also take place during a gap in the Observe phase of the PI procedure.

In the PI procedure as used in the present study, responses are centered on the memory representation of a just-encoded interval, which is made possible by varying the target interval from trial to trial. Although this was not among the main objectives of the present study, this made it possible to test whether the various measures differ with varying target durations; for example, whether peak times and spreads generally increase with increasing target duration, as in previous studies (Kladopoulos et al., 1998; Rakitin et al., 1998). Besides, measures of variability, independent of estimated durations, were computed by dividing spreads by peak times. Another measure of variability independent of estimated durations was the coefficient of variation (CV), computed by dividing the standard deviation of peak times by mean peak time.

Finally, previous studies examined the relative contributions of memory and threshold variance in human timing with analyses of correlations between various measures in the PI (Rakitin et al., 1998) and the start-stop (Kladopoulos et al., 1998) procedures. More precisely, positive correlations between start and stop times and slightly positive correlations between spreads and peak times were obtained, suggesting a strong contribution of memory processes. Moderate or weak negative correlations between start and spread times also suggested that some variability was related to response threshold variability. These conclusions were similar to those in animal studies (e.g., Cheng \& Miceli, 1996; Cheng \& Westwood, 1993; Church, Meck, \& Gibbon, 1994; Matell, Bateson, \& Meck, 2006), revealing notable similarities in timing with humans, birds, and rodents (see Penney, Gibbon, \& Meck, 2008). Correlations were also analyzed to examine the contribution of memory and threshold processes in the present study.

\section{EXPERIMENT 1}

\section{Method}

\section{Participants}

Sixteen participants ( 8 women and 8 men) between 20 and 44 years of age $(M=25.04, S D=6.57)$ were paid $\$ 5$ to take part in the experiment. They were all students at Laval University, recruited through advertisement on the campus. They were naive to the purpose of the experiment.

\section{Stimuli and Apparatus}

Stimulus and feedback presentation as well as data collection were controlled by an Apple Macintosh computer, using a color CRT monitor. Participants sat at a distance of about $60 \mathrm{~cm}$ from the screen. The participant's preferred hand rested on the space bar of the computer keyboard. Participants were instructed to place their forearms in the most comfortable position on the computer tables in order to ensure maximum stability in response production. The space bar was used for response production. The Enter key was also used to initiate and end trials. To start the practice and experimental sessions, the participant could press any key of the keyboard. The same tone $(600 \mathrm{~Hz}, 60 \mathrm{~dB})$ was used throughout the experiment.

\section{Procedure}

A trial started with the message "Press the Enter key to start trial," displayed in the center of the screen. When the Enter key was pressed, the word Observe was presented for $1 \mathrm{sec}$. This word prompted participants to pay attention to the tone that immediately followed. The target duration was presented with an uninterrupted tone that lasted for $2.4,3.2$, or $4.0 \mathrm{sec}$ in trials with no gap (see top panel of Figure 1). There was a 0.5 -sec pause after the end of the tone. The word Produce then appeared in the middle of the computer screen for $1 \mathrm{sec}$, forewarning participants that they should prepare to reproduce the target duration. The disappearance of the word Produce coincided with the beginning of a tone. After judging that the duration of the tone was close to the duration of the tone presented in the Observe phase, the participant started to press the space bar repeatedly until certain that the target duration was over. The participant could then terminate the trial by pressing the Enter key. The program included an automatic termination of the trial if the stimulus lasted for three times the target duration.

As illustrated at the bottom of Figure 1, trials were identical with trials with gap, except that during the Observe phase, there was a gap in tone presentation after $25 \%$ or $75 \%$ of its duration had elapsed. The gap lasted for 1 or $2 \mathrm{sec}$, after which the tone presentation resumed until the total tone presentation reached the target duration to be reproduced $(2.4,3.2$, or $4.0 \mathrm{sec})$. As in no-gap trials, the total tone duration (which represented a sum of pregap and postgap durations) was reproduced in the Produce phase with multiple responses centered on the remembered target duration.

Participants were asked to center their responses on the target duration by pressing the space bar on the computer keyboard as many times as necessary. In practice trials with feedback, feedback was presented in the form of a histogram showing the relative distribution of responses around the target duration (see top panel of Fig- 
ure 1). The feedback was designed to encourage symmetrical and evenly distributed responses. It remained on the screen for $4 \mathrm{sec}$, but its presentation could be terminated if the participant pressed the Enter key. There was then a blank screen for $1 \mathrm{sec}$, followed by a message announcing the beginning of the next trial. There was a 30 -sec pause between each block of the experimental session.

The feedback showed a distribution of responses in a given trial plotted on a relative time scale (each time bin represented one tenth of the target duration) and on a relative response scale (proportion of maximum responses per bin; see Rakitin et al., 1998, for identical use of feedback in the PI procedure). This way, the participants had no information about the absolute value of the target duration, which was indicated below the ordinate by the letter T. Participants could acquire two different kinds of information from this feedback. First, how stringent their response threshold was; if they were setting a tight response threshold around their representation of the duration to be timed, the width of the distribution was relatively narrow, whereas if the threshold was less stringent, the distribution was wider. In addition, they received information about how accurately their responses were centered on the target duration. If most of their responses were to the left of the letter T, they were producing their responses too early, but if their responses were generally to the right of the letter T, they tended to respond too late.

As usual in the PI task, the main measures considered in data analyses were the start time, the stop time, and measures derived from these times: the peak time and the spread of response distribution. These measures are illustrated in Figure 1 (top panel), the start time being the time between the beginning of tone presentation in the Produce phase and the first response in the trial, and the stop time being the time between the beginning of the tone in the Produce phase and the last response. The peak time is computed as the "middle time" derived from the high state of individual trials; that is, as the arithmetic mean of the start and stop values in each trial. Because participants tried to center their window of responses on the duration to be reproduced, the peak time is taken as an index of the remembered target duration in that trial. The difference between the stop and start time values represents the "spread" of response distribution and is considered as an index of variability in that trial.

Participants were instructed neither to count nor to use any other process of interval subdivision - such as foot tapping, for example. A postexperimental questionnaire was also administered, in which the participants were asked what strategies had been used in order to estimate time. All participants reported having followed the instructions regarding strategies in the questionnaire. Participants were also asked to press the space bar at least four times, in order to produce a response distribution on each trial. No external timing device, such as a wristwatch, was allowed in the test room.

Participants were tested individually in one practice session immediately followed by one experimental session. There were also practice trials at the beginning of the experimental session, as described below. In the practice session, the target durations were different from those used in experimental trials, whereas in practice trials performed at the beginning of the experimental session, the target durations were the same as those in the experimental trials. This way, the participants were gradually familiarized with the task and the experimental setting in the practice session, then with the specific experimental task in the practice trials of the experimental session. This sequence was tested in a pilot study before the beginning of the experiment and led to stable temporal performance, despite the relative complexity of the task in the PI procedure with gaps and the multiple responses required in this task. Overall, the experiment (including practice and experimental sessions) lasted for approximately $40 \mathrm{~min}$.

Practice session. The objective of the practice session was to familiarize participants with the task and experimental setting. The experimenter was present in the testing room to answer any question about the task and procedure. The practice session consisted of 10 trials divided into five blocks of 2 trials. The first block was a demonstration block in which participants were instructed to pay attention to two tones ( 4.6 and $5.4 \mathrm{sec}$ ) whose duration was to be reproduced in the practice session. In each trial of the second and third blocks, one of the two demonstration tones was presented, and participants were asked to reproduce its duration. Feedback was provided in the second block to inform the participant about the accuracy of their temporal reproduction, but there was no feedback in the third block. In the fourth and fifth blocks, there was a gap in tone presentation, and the task was to reproduce the total duration of the tone, which corresponded to the sum of the pregap and postgap durations. In the fourth block, a feedback was presented after the reproduction, whereas there was no feedback in the fifth block.

Experimental session. The experimental session was composed of seven blocks; that is, four blocks of practice trials followed by three blocks of experimental trials. The first four blocks included 12 practice trials, and each of the three experimental blocks included 24 trials, so that there were 48 practice trials in all and each participant completed 72 experimental trials. The first four blocks were identical to the first four blocks of the practice session: demonstration block, block of time reproduction with feedback, block without feedback, and block with gap with feedback. These were followed by three experimental blocks of time reproduction with gap with no feedback (Blocks 5, 6, and 7), which were identical to the fifth block of the practice session.

The three target durations to be reproduced throughout the experimental session were $2.4,3.2$, and $4.0 \mathrm{sec}$. The first three practice blocks (with no gap, no feedback) contained 12 trials, with 4 trials for each of the three target durations. In the fourth block, in which a feedback was provided, combining the three target durations with different values of gap location ( $25 \%$ or $75 \%$ of the target duration) and of gap duration ( $1 \mathrm{or} 2 \mathrm{sec}$ ) resulted in 12 types of trial; there was 1 trial corresponding to each of those. There was no feedback in the fifth, sixth, and seventh blocks, which were otherwise identical to the fourth block. Within a block, the target duration to be reproduced, as well as the duration and location of the gap, varied randomly from trial to trial, with the constraint that there was an equal number of trials at each combination of target duration, gap duration, and gap location.

\section{Data Analyses}

For each participant, means and standard deviations of peak times and spread times were computed at each combination of factor level (target duration, gap location, and gap duration). Spreads were divided by peak times for each participant and combination of variables to obtain a "spread/peak-time ratio"; that is, a measure of variability independent from peak-time values.

At each combination of factor level, a CV of middle times was also computed for each participant by dividing the standard deviation of middle times by the mean middle time (middle time $=$ peak time). Mean peak times, spreads, spread/peak-time ratios and CVs were submitted to univariate ANOVAs with three repeated factors: target duration $(2.4,3.2$, or $4.0 \mathrm{sec})$, gap location $(25 \%$ or $75 \%$ of target duration) and gap duration (1 or $2 \mathrm{sec})$. The alpha level was set at .05 .

\section{Results}

Table 1 presents the means and standard deviations of peak times, start times, stop times, spreads, spread/peak-time ratios, and CVs of peak times for the target duration and gap location values. The data are averaged over gap duration. Results from ANOVAs on peak times, spreads, spread/peak-time ratios and CVs are summarized in Table 2.

Peak times increased significantly with increasing target duration. More importantly, peak times were significantly affected by varying gap location, because peak times were shorter at the onset of the gap, when $75 \%$ of the target interval had elapsed, than when only $25 \%$ of 
Table 1

Experiment 1: Means and Standard Deviations of Peak Times, Start Times, Stop Times, Spreads, Spread/Peak-Time Ratios, and Coefficients of Variation (CVs) of Peak Times by the Target Duration and Gap Location Values

\begin{tabular}{|c|c|c|c|c|c|c|c|c|c|c|c|c|}
\hline \multirow{2}{*}{$\begin{array}{c}\text { Target } \\
\text { Duration }\end{array}$} & \multicolumn{2}{|c|}{ Peak Time } & \multicolumn{2}{|c|}{ Start Time } & \multicolumn{2}{|c|}{ Stop Time } & \multicolumn{2}{|c|}{ Spread } & \multicolumn{2}{|c|}{$\begin{array}{c}\text { Speed/Peak } \\
\text { Time }\end{array}$} & \multicolumn{2}{|c|}{$\mathrm{CV}$} \\
\hline & $M$ & $S D$ & $M$ & $S D$ & $M$ & $S D$ & $M$ & $S D$ & $M$ & $S D$ & $M$ & $S D$ \\
\hline \multicolumn{13}{|l|}{$2.4 \mathrm{sec}$} \\
\hline GL 25 & 2.95 & 0.40 & 2.48 & 0.38 & 3.43 & 0.46 & 0.94 & 0.26 & 0.32 & 0.09 & 0.14 & 0.04 \\
\hline GL 75 & 2.74 & 0.51 & 2.28 & 0.52 & 3.20 & 0.53 & 0.92 & 0.26 & 0.35 & 0.12 & 0.18 & 0.07 \\
\hline \multicolumn{13}{|l|}{$3.2 \mathrm{sec}$} \\
\hline GL 25 & 3.48 & 0.38 & 2.98 & 0.41 & 3.98 & 0.42 & 1.00 & 0.32 & 0.29 & 0.10 & 0.12 & 0.04 \\
\hline GL 75 & 3.27 & 0.51 & 2.79 & 0.53 & 3.74 & 0.51 & 0.95 & 0.26 & 0.30 & 0.10 & 0.14 & 0.05 \\
\hline \multicolumn{13}{|l|}{$4.0 \mathrm{sec}$} \\
\hline GL 25 & 3.92 & 0.43 & 3.42 & 0.46 & 4.43 & 0.45 & 1.01 & 0.28 & 0.26 & 0.08 & 0.12 & 0.04 \\
\hline GL 75 & 3.80 & 0.49 & 3.30 & 0.54 & 4.30 & 0.47 & 1.00 & 0.28 & 0.27 & 0.09 & 0.13 & 0.05 \\
\hline
\end{tabular}

the target interval had elapsed. The effect of gap location was present at all three target durations, and there was no interaction between gap location and target duration. A marginal effect of gap duration was that peak times were longer when the gap was longer $(p=.052)$. There was an interaction between gap location and gap duration, illustrated in Figure 2, revealing a stronger effect of gap location when the gap was shorter (solid lines in Figure 2). Contrasts showed that the difference in mean peak times at the two gap locations was statistically significant when the gap duration was $1 \mathrm{sec}[F(1,15)=11.57$, $p=.004]$, but that, although peak times were shorter at the higher value of gap location when the gap was $2 \mathrm{sec}$ also, the effect did not reach significance $[F(1,15)=$ $1.94, p=.18]$.

Spreads increased significantly with increasing target duration. Although spreads decreased when the gap occurred later, the effect did not reach statistical significance $(p=.07)$. However, there was a significant effect of gap duration: The spread was greater when the gap was longer ( 0.9559 vs. 0.9862 when the gap was 1 and 2 sec, respectively). None of the interactions was significant.

Spread/middle-peak ratios decreased significantly with increasing target duration $(0.337,0.295$, and 0.265 at 2.4 , 3.2 , and $4.0 \mathrm{sec}$, respectively) but did not vary as a function of either gap location or gap duration. None of the interactions in the analysis on spread/middle-peak ratios was significant.

CVs varied neither as a function of gap location nor as a function of gap duration, but CVs were negatively related to target duration $(0.159,0.132$, and 0.126 at $2.4,3.2$, and $4.0 \mathrm{sec}$ ). None of the interactions in the analysis on CVs was significant.

Correlations between start and stop times, start times and spreads, and peak times and spreads were computed for each participant at each combination of target duration, gap location, and gap duration values. Mean correlations, averaged over participants, are presented in Table 3,

Table 2

Experiment 1: Results of ANOVAs on Peak Times, Spreads, Spread/Peak-Time Ratios, and Coefficients of Variation (CVs) of Middle Times

\begin{tabular}{lrcccc}
\hline & & \multicolumn{4}{c}{$F$ Values and Mean Square Errors } \\
\cline { 3 - 6 } \multicolumn{1}{c}{ Source } & $d f$ & Peak Time & Spread & Spread/Peak \\
\hline Target duration (TD) & 2 & $122.453^{* * *}$ & $4.360^{*}$ & $26.737^{*}$ & $7.611^{* *}$ \\
Error & 30 & 0.135 & 0.018 & 0.003 & 0.003 \\
Gap location (GL) & 1 & $6.358^{*}$ & 3.954 & 2.801 & 2.826 \\
Error & 15 & 0.025 & 0.011 & 0.003 & 0.006 \\
Gap duration (GD) & 1 & 4.474 & $6.272^{*}$ & 0.242 & 0.028 \\
Error & 15 & 0.391 & 0.007 & 0.002 & 0.003 \\
TD $\times$ GL & 2 & 1.248 & 1.106 & 1.673 & 1.353 \\
Error & 30 & 0.036 & 0.010 & 0.002 & 0.002 \\
TD $\times$ GD & 2 & 2.339 & 1.480 & 0.019 & 0.640 \\
Error & 30 & 0.081 & 0.009 & 0.001 & 0.002 \\
GL $\times$ GD & 1 & $4.760^{*}$ & 0.054 & 0.271 & 2.133 \\
Error & 15 & 0.044 & 0.011 & 0.001 & 0.003 \\
TD $\times$ GL $\times$ GD & 2 & 0.387 & 1.783 & 2.217 & 0.292 \\
Error & 30 & 0.036 & 0.007 & 0.001 & 0.003 \\
\hline Note Spred/peak
\end{tabular}

Note - Spread $/$ peak time $=$ spread/peak-time ratios; $\mathrm{CVs}$ of peak times $=S D$ of peak times/peak times. ${ }^{*} p<.05 .{ }^{* *} p<.01 . \quad{ }^{* * *} p<.001$. 


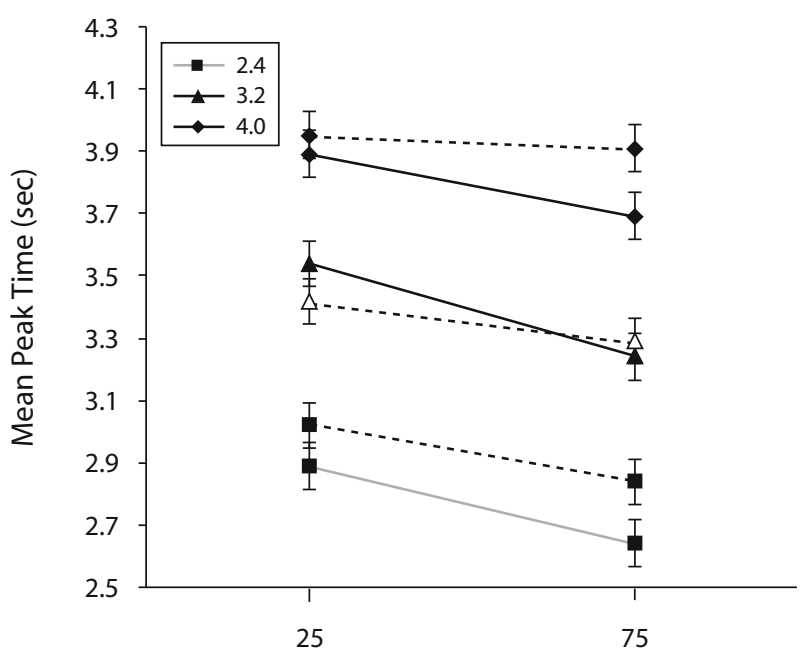

Gap Location (\% of Target Duration)

Figure 2. Experiment 1: Mean peak times as a function of gap location values, at each value of target duration $(2.4,3.2$, and $4.0 \mathrm{sec}$ ), and each value of gap duration (1 sec [solid line] and 2 sec [dotted line]). Error bars are standard errors of the means computed with a pooled mean square error.

at each value of target duration. Means of individual correlations were similar at all three target durations: very high and positive between start times and stop times, very small and negative between start times and spreads, and moderate and positive between middle times and spread. Repeated measures ANOVAs including the target duration, gap location and gap duration factors were performed on individual correlations; results from these analyses are summarized in Appendix A. Neither the factors included in the analyses nor the interactions between these factors affected correlations significantly.

The correlations presented in Table 3 are means of correlations computed for each individual participant. In order to test whether the start-stop, start-spread, and peak-time-spread correlations were significant, group correlations were computed and tested (two-tailed test) using all trials of all participants. The group start-stop correlation was $.90(p<.001)$, the start-spread correlation was -.04 $(p>.05)$, and the peak-time-spread correlation was $.10(p<.001)$.

Start-stop, start-spread, and peak-time-spread correlations were finally computed in practice trials with no feedback and no gap. These trials were performed in the third block of the experimental session before introducing trials with gaps, so that in this third block, participants were not expecting a gap. Correlations were computed using all practice trials, including all participants. In those trials, the start-stop, start-spread, and peak-time-spread correlations were $.93,-.11$, and .08 , respectively.

The mean and standard deviation of the number of responses provided in experimental trials were computed at each of the three target durations. At the 2.4-, 3.2-, and $4.0-\mathrm{sec}$ intervals, those means (and standard deviations) were, respectively, 6.41 (2.03), 6.65 (2.18), and 6.72
(2.21), which showed that the number of responses varied little with the interval to reproduce.

\section{Discussion}

Peak times were shorter when the gap occurred later during the tone presentation to reproduce. This result supports previous findings obtained with a time production paradigm (Fortin \& Massé, 2000), and shows that perceived time is shortened when the gap occurs later during the interval to be encoded in the PI procedure. This shortening was interpreted previously as revealing an effect of gap expectancy on perceived time; results in Experiment 1 show that this effect can also be observed when the gap location manipulation takes place during the encoding of a target duration in the PI procedure. However, the effect of gap location was weaker and did not reach statistical significance when the gap duration was longer in the present experiment. One possible interpretation might be that when the gap is shorter, the encoded value of the pregap duration used in the Produce phase is more precise, so that the effect of manipulating its duration (the pregap duration being equivalent to the value of gap location) is more easily detected.

Using gaps in the PI procedure revealed a decrease of variability in responding with increasing values of gap location, showing a clear relationship between variability in response reproduction and perceived time. Peak times tended to be longer when the gap was longer, which may be explained by an effect of preparation during the gap: a longer gap would allow participants to reach a higher level of readiness to resume timing at the end of the gap than would a shorter one (see MacDonald \& Meck, 2004, for a discussion of the role of preparatory intervals in duration discrimination). Resuming timing more quickly because of this preparation would result in a relatively higher amount of temporal information accumulated in the postgap period, leading to a longer perceived interval. The tendency of peak times to be longer with increasing gap duration supports previous results suggesting that preparation may take place during gaps in time production (Fortin et al., 2005).

Both the spread/peak-time ratio and the $\mathrm{CV}$ decreased with increasing target duration. Similar results with the same measures were obtained in previous studies using the start-stop procedure and the PI procedure (Kladopoulos et al., 1998; Rakitin et al., 1998). This decrease of time-independent measures of variability shows that, although variability as measured by the spread increases with longer target intervals, this increase is not in direct

Table 3

Experiment 1: Means of Individual Start-Stop, Start-Spread, and Peak-Time-Spread Correlations at the Three Target Durations

\begin{tabular}{lrrr}
\hline & \multicolumn{3}{c}{ Target Duration (sec) } \\
\cline { 2 - 4 } & \multicolumn{1}{c}{2.4} & \multicolumn{1}{c}{3.2} & \multicolumn{1}{c}{4.0} \\
\hline Start-stop & .916 & .924 & .870 \\
Start-spread & -.074 & -.003 & -.025 \\
Peak-time-spread & .094 & .168 & .183 \\
\hline
\end{tabular}


proportion to the target duration. In the PI procedure, one possible explanation is that the minimum number of required responses, four, was the same at all target durations. The time needed to execute these responses was relatively shorter as the target duration increased, which could result in lower variability for longer durations.

The pattern of start-stop, start-spread, and peak-timespread correlations supported results from previous studies. High and positive correlations between start times and stop times, and moderate and positive correlations between peak times and spreads suggest a strong contribution of memory processes in the PI procedure with gaps. Although negative, correlations between start and spread were very low and close to zero, suggesting a very small contribution of response threshold processes.

Overall, the shifts in peak times observed when gaps are introduced in the PI procedure with humans generally support the conclusions of studies using a time reproduction method. Note that in experimental sessions of the present study, there were 12 practice trials with gaps, including feedback on accuracy of temporal performance. These trials, otherwise identical to the following experimental trials in which no feedback was presented, were included in order to lead to performance as stable as possible in the PI procedure with gaps. Although these trials could have reduced or changed effects of gap manipulations in comparison with other procedures in which gap values were varied, effects generally consistent with previous results were found on peak times. Besides, spread values were generally related to peak times; they increased with increasing target duration, they were lower at the late gap location, and they tended to be higher at the longest gap duration.

\section{EXPERIMENT 2}

The shortening of perceived duration with increasing pregap duration is attributed to gap expectancy. According to this hypothesis, the effect should therefore be independent on the gap presence and should be strongest when participants are expecting a gap for the longest time- - for example, during a signal presented when no gap occurs but one is expected throughout. In Experiment 2, the procedure was similar to that in Experiment 1, except that there were some trials with no gaps in the experimental trials. In these trials, which could be seen as catch trials because participants are expecting a gap that never occurs, the reproduced duration should be even shorter than in trials with gaps. Assuming that participants expect the gap until the signal presentation is ended, these trials with no gaps may be considered as trials in which participants are expecting a gap for about $100 \%$ of the signal presentation (Fortin \& Massé, 2000; Fortin \& Tremblay, 2006). Trials with no gaps were therefore considered thereafter as representing the highest value of the gap location factor, which then included three levels: $25 \%, 75 \%$, and nogap trials, considered as roughly equivalent to $100 \%$ of target duration. This condition permitted us to examine the effect of gap expectancy, independently of actual gap occurrence, on the various measures recorded in the PI procedure.

\section{Method}

\section{Participants}

Fifteen participants ( 8 women and 7 men), ranging in age from 20 to 48 years $(M=26.56, S D=8.90)$, were paid $\$ 5$ each to take part in the experiment. They were all students at Laval University, recruited through advertisement on the campus. They had not participated in the first experiment of the study and were naive to the purpose of the experiment.

\section{Stimuli and Apparatus}

The stimuli and apparatus were identical to those in Experiment 1 .

\section{Procedure}

The procedure was the same as in Experiment 1 in both practice and experimental trials, but with the following exceptions in experimental trials. The experimental session included 90 trials, 72 trials with gaps, and 18 trials with no gaps. This was achieved by adding 18 trials with no gaps in the three experimental blocks; that is, 6 trials with no gap per block. There were therefore 30 experimental trials in each of the three experimental blocks, 24 with gaps and 6 with no gaps. We slightly changed the values of gap duration, 2 and $3 \mathrm{sec}$ (rather than 1 and $2 \mathrm{sec}$, as in Experiment 1) to enhance the generality of results. Target duration $(2.4,3.2$, and $4.0 \mathrm{sec}$ ) and gap duration ( 2 and $3 \mathrm{sec}$ ) varied randomly from trial to trial within blocks of trials, as in Experiment 1. The three types of trials defined by gap location $(25 \%$ and $75 \%)$ in trials with gaps and by the absence of a gap (no-gap trials) were presented in equal number (one third of the trials at $25 \%$ and at $75 \%$, as well as of no-gap trials) within a block of trials, and were presented in random order from trial to trial.

\section{Results}

The means and standard deviations of peak times, start times, stop times, spreads, spread/peak-time ratios, and CVs of peak times at each target duration and gap location condition, which was a $25 \%$, a $75 \%$, or a no-gap trial, are presented in Table 4. The data are averaged over gap duration.

Two ANOVAs were carried out on each measure: one with two factors, target duration $(2.4,3.2$, and $4.0 \mathrm{sec})$ and gap location $(25 \%, 75 \%$, and no gap), and one with three factors, target duration, gap location, and gap duration $(2$ and $3 \mathrm{sec}$ ). The two-factor ANOVA included data from all trials, including trials with no gap. In that analysis, the gap duration factor was not included, because this factor was irrelevant in trials with no gap. The three-factor ANOVA was performed on measures collected in trials with gaps only, so the gap duration factor was included. Results from two-factor and three-factor ANOVAs are summarized in Table 5.

In both ANOVAs, peak times increased significantly with increasing target duration. More importantly, both ANOVAs showed that peak times were significantly shorter with increasing value of gap location, shortest peak times being obtained in trials with no gap, as illustrated in Figure 3. In the three-factor ANOVA, the effect of gap duration was not significant and none of the interactions reached significance.

None of the factors included in the analyses influenced spread times significantly. However, as in Experiment 1, spread/peak-time ratios decreased significantly, with increasing target duration in both ANOVAs. Although the effect did not reach statistical significance, spread/ peak-time ratios tended to increase with increasing gap 
Table 4

Experiment 2: Means and Standard Deviations of Peak Times, Start Times, Stop Times, Spreads, Spread/Peak-Time Ratios, and Coefficients of Variation (CVs) of Peak Times by the Target Duration and Gap Location Values, Including No-Gap Trials

\begin{tabular}{|c|c|c|c|c|c|c|c|c|c|c|c|c|}
\hline \multirow{2}{*}{$\begin{array}{c}\text { Target } \\
\text { Duration }\end{array}$} & \multicolumn{2}{|c|}{ Peak Time } & \multicolumn{2}{|c|}{ Start Time } & \multicolumn{2}{|c|}{ Stop Time } & \multicolumn{2}{|c|}{ Spread } & \multicolumn{2}{|c|}{$\begin{array}{c}\text { Spread/Peak } \\
\text { Time } \\
\end{array}$} & \multicolumn{2}{|c|}{$\mathrm{CV}$} \\
\hline & $M$ & $S D$ & $M$ & $S D$ & $M$ & $S D$ & $M$ & $S D$ & $M$ & $S D$ & $M$ & $S D$ \\
\hline \multicolumn{13}{|l|}{$2.4 \mathrm{sec}$} \\
\hline GL 25 & 3.01 & 0.38 & 2.60 & 0.34 & 3.42 & 0.45 & 0.82 & 0.28 & 0.27 & 0.08 & 0.16 & 0.07 \\
\hline GL 75 & 2.81 & 0.41 & 2.42 & 0.38 & 3.20 & 0.47 & 0.79 & 0.25 & 0.28 & 0.08 & 0.15 & 0.05 \\
\hline No gap & 2.55 & 0.39 & 2.15 & 0.33 & 2.95 & 0.47 & 0.81 & 0.25 & 0.32 & 0.07 & 0.14 & 0.10 \\
\hline \multicolumn{13}{|l|}{$3.2 \mathrm{sec}$} \\
\hline GL 25 & 3.46 & 0.41 & 3.06 & 0.38 & 3.86 & 0.46 & 0.80 & 0.26 & 0.23 & 0.07 & 0.12 & 0.04 \\
\hline GL 75 & 3.34 & 0.42 & 2.94 & 0.38 & 3.74 & 0.49 & 0.80 & 0.26 & 0.24 & 0.07 & 0.13 & 0.05 \\
\hline No gap & 3.19 & 0.35 & 2.81 & 0.36 & 3.57 & 0.37 & 0.75 & 0.24 & 0.24 & 0.08 & 0.14 & 0.08 \\
\hline \multicolumn{13}{|l|}{$4.0 \mathrm{sec}$} \\
\hline GL 25 & 3.90 & 0.37 & 3.50 & 0.34 & 4.31 & 0.44 & 0.81 & 0.26 & 0.21 & 0.06 & 0.11 & 0.04 \\
\hline GL 75 & 3.89 & 0.54 & 3.48 & 0.51 & 4.30 & 0.61 & 0.82 & 0.27 & 0.21 & 0.06 & 0.12 & 0.04 \\
\hline No gap & 3.63 & 0.26 & 3.23 & 0.25 & 4.03 & 0.34 & 0.80 & 0.27 & 0.22 & 0.07 & 0.11 & 0.05 \\
\hline
\end{tabular}

Note-GL, gap location. Times are in seconds.

location $(0.237,0.244$, and 0.258 at $25 \%, 75 \%$, and nogap trials, respectively; $p=.054)$. There was a significant interaction, however, between target duration and gap location to the extent that spread/peak-time ratios were larger when the gap occurred later or never occurred, but only when the target duration was $2.4 \mathrm{sec}$. This was confirmed in tests of simple main effects, which showed that the effect of location on spread/peak-time ratios was significant when the target duration was $2.4 \sec [F(2,28)=$ $11.02, p<.001]$, but not when the target duration was 3.2 or $4.0 \mathrm{sec}$ (both $F \mathrm{~s}<1$; ratios $=0.27,0.28$, and 0.32 at $2.4 \mathrm{sec}, 0.23,0.24$, and 0.24 at $3.2 \mathrm{sec}$, and $0.21,0.21$, and 0.22 at $4.0 \mathrm{sec}$ ). A posteriori comparisons with Bonferroni adjustments showed that the significant effect at the 2.4-sec target duration was caused essentially by including trials with no gap: Ratios did not differ whether the gap was located at $25 \%$ or at $75 \%$ of the target duration $(M=$ $0.27, S D=0.08$ at $25 \% ; M=0.28, S D=0.08$ at $75 \%)$, but were significantly larger in trials with no gap $(M=$ $0.32, S D=0.07)$ than in trials where the gap was located

Table 5

Experiment 2: Results of ANOVAs on Peak Times, Spreads, Spread/Peak-Time Ratios, and Coefficients of Variation (CVs) of Peak Times

\begin{tabular}{|c|c|c|c|c|c|}
\hline \multirow[b]{2}{*}{ Source } & \multirow[b]{2}{*}{$d f$} & \multicolumn{4}{|c|}{$F$ Values and Mean Square Errors } \\
\hline & & Peak Time & Spread & $\begin{array}{l}\text { Spread/Peak } \\
\text { Time }\end{array}$ & $\mathrm{CV}$ \\
\hline \multicolumn{6}{|c|}{ Two-Factor ANOVA } \\
\hline $\begin{array}{l}\text { Target duration (TD) } \\
\text { Error }\end{array}$ & $\begin{array}{r}2 \\
28\end{array}$ & $\begin{array}{c}201.025^{* * *} \\
0.058\end{array}$ & $\begin{array}{l}2.026 \\
0.004\end{array}$ & $\begin{array}{l}81.351^{* * *} \\
0.001\end{array}$ & $\begin{array}{l}8.251^{* *} \\
0.002\end{array}$ \\
\hline $\begin{array}{l}\text { Gap location (GL) } \\
\text { Error }\end{array}$ & $\begin{array}{r}2 \\
28\end{array}$ & $\begin{array}{l}9.104^{* *} \\
0.015\end{array}$ & $\begin{array}{l}1.412 \\
0.005\end{array}$ & $\begin{array}{l}3.237 \\
0.002\end{array}$ & $\begin{array}{l}0.100 \\
0.004\end{array}$ \\
\hline $\begin{array}{l}\mathrm{TD} \times \mathrm{GL} \\
\text { Error }\end{array}$ & $\begin{array}{r}4 \\
56\end{array}$ & $\begin{array}{l}1.804 \\
0.036\end{array}$ & $\begin{array}{l}2.179 \\
0.003\end{array}$ & $\begin{array}{l}5.014 \\
0.00004\end{array}$ & $\begin{array}{l}0.505 \\
0.002\end{array}$ \\
\hline \multicolumn{6}{|c|}{ Three-Factor ANOVA } \\
\hline $\begin{array}{l}\text { Target duration (TD) } \\
\text { Error }\end{array}$ & $\begin{array}{r}2 \\
28\end{array}$ & $\begin{array}{c}164.415^{* * *} \\
0.089\end{array}$ & $\begin{array}{l}0.641 \\
0.004\end{array}$ & $\begin{array}{l}58.707^{* * *} \\
0.001\end{array}$ & $\begin{array}{l}18.337^{* * *} \\
0.001\end{array}$ \\
\hline $\begin{array}{l}\text { Gap location (GL) } \\
\text { Error }\end{array}$ & $\begin{array}{r}1 \\
14\end{array}$ & $\begin{array}{l}8.098^{*} \\
0.007\end{array}$ & $\begin{array}{l}1.012 \\
0.005\end{array}$ & $\begin{array}{l}1.523 \\
0.002\end{array}$ & $\begin{array}{l}0.461 \\
0.004\end{array}$ \\
\hline $\begin{array}{l}\text { Gap duration (GD) } \\
\text { Error }\end{array}$ & $\begin{array}{r}1 \\
14\end{array}$ & $\begin{array}{l}0.035 \\
0.036\end{array}$ & $\begin{array}{l}0.167 \\
0.007\end{array}$ & $\begin{array}{l}0.307 \\
0.001\end{array}$ & $\begin{array}{l}0.373 \\
0.003\end{array}$ \\
\hline $\begin{array}{l}\mathrm{TD} \times \mathrm{GL} \\
\text { Error }\end{array}$ & $\begin{array}{r}2 \\
28\end{array}$ & $\begin{array}{l}2.198 \\
0.064\end{array}$ & $\begin{array}{l}2.65 \\
0.003\end{array}$ & $\begin{array}{l}0.331 \\
0.001\end{array}$ & $\begin{array}{l}0.764 \\
0.003\end{array}$ \\
\hline $\begin{array}{l}\mathrm{TD} \times \mathrm{GD} \\
\text { Error }\end{array}$ & $\begin{array}{r}2 \\
28\end{array}$ & $\begin{array}{l}1.749 \\
0.029\end{array}$ & $\begin{array}{l}0.627 \\
0.003\end{array}$ & $\begin{array}{l}0.155 \\
0.0002\end{array}$ & $\begin{array}{l}0.918 \\
0.002\end{array}$ \\
\hline $\begin{array}{l}\mathrm{GL} \times \mathrm{GD} \\
\text { Error }\end{array}$ & $\begin{array}{r}1 \\
14\end{array}$ & $\begin{array}{l}1.430 \\
0.050\end{array}$ & $\begin{array}{l}0.595 \\
0.010\end{array}$ & $\begin{array}{l}2.109 \\
0.001\end{array}$ & $\begin{array}{l}0.448 \\
0.002\end{array}$ \\
\hline $\begin{array}{l}\mathrm{TD} \times \mathrm{GL} \times \mathrm{GD} \\
\text { Error }\end{array}$ & $\begin{array}{r}2 \\
28\end{array}$ & $\begin{array}{l}0.570 \\
0.022\end{array}$ & $\begin{array}{l}2.153 \\
0.007\end{array}$ & $\begin{array}{l}0.726 \\
0.001\end{array}$ & $\begin{array}{l}1.444 \\
0.002\end{array}$ \\
\hline
\end{tabular}




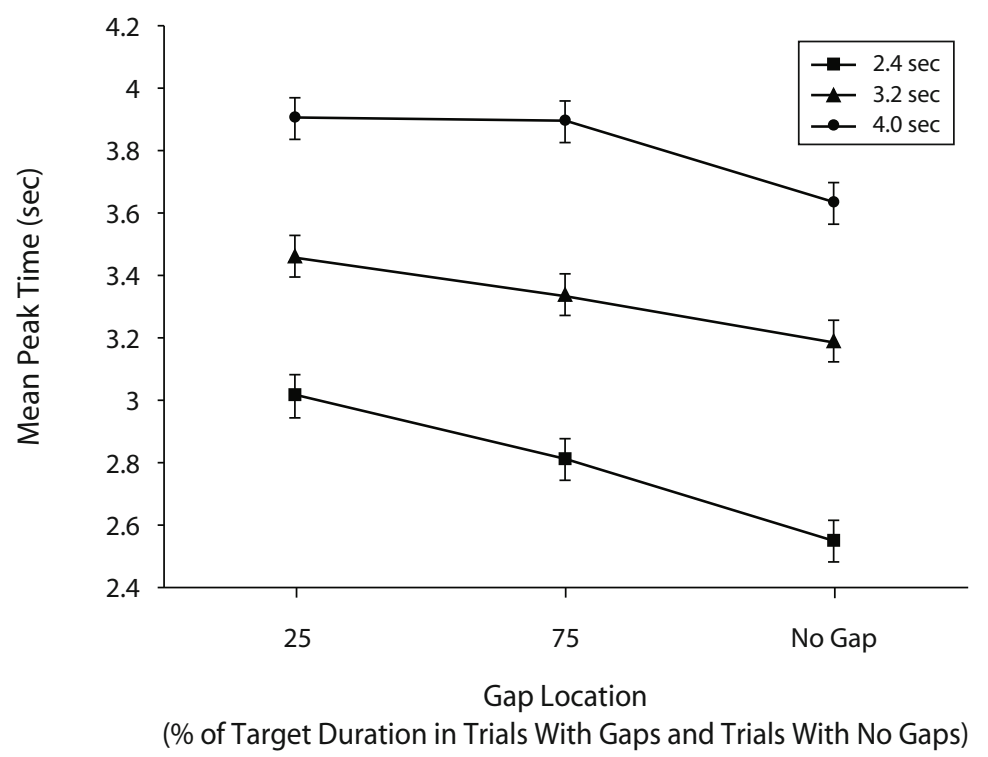

Figure 3. Experiment 2: Mean peak times as a function of duration of gap expectancy (corresponding approximately to $25 \%$ and $75 \%$ of target duration in trials with gaps and to $100 \%$ of target duration in trials with no gaps), at each value of target duration: 2.4, 3.2, and 4.0 sec. Error bars are standard errors of the means computed with a pooled mean square error.

at $25 \%$ or $75 \%$. In both ANOVAs, none of the other factors or of the interactions between factors affected spread/ peak-time ratios significantly.

CVs of peak times were significantly smaller when the target duration was longer in the two ANOVAs, but neither the gap location nor its duration affected CVs significantly. None of the interactions was significant.

For each participant, correlations between start and stop times, start times and spreads, and between peak times and spreads were computed at each combination of target duration, gap location, and gap duration values. Mean correlations, presented in Table 6, were strikingly similar to those obtained in experimental trials of Experiment 1. Correlations between start and stop were high and positive, those between start and spread were mostly negative but close to zero, and correlations between peak time and spread were moderate and positive. Results from a univariate repeated measures ANOVA performed on these correlations with target duration (three levels, 2.4, 3.2, and $4.0 \mathrm{sec}$ ) and gap location (three levels, 25\%, 75\%, and no-gap trials) are summarized in Appendix B. As in Experiment 1, correlations did not vary with any of the factors included in the analysis.

Correlations presented in Table 6 are means of individual correlations. Group correlations were also computed as in Experiment 1, using all the data from all participants. Group start-stop, start-spread, and peak-time-spread correlations were, respectively, $.92(p<.001),-.02(p>$ $.05)$, and $.16(p<.001)$. As in Experiment 1 , the group start-stop and peak-time-spread correlations were both significant, but the start-spread correlation was not.

Start-stop, start-spread, and peak-time-spread correlations, computed in all trials over all participants, were, respectively, .91, -.01 , and .15 in practice trials with no feedback and no gap. Note that gaps were not expected in those practice trials.

The number of responses did not seem influenced by the interval to reproduce, as was found in Experiment 1. The means and standard deviations of the number of responses provided in experimental trials were 5.40 (1.34), 5.38 (1.27), and 5.47 (1.32) at the 2.4-, 3.2-, and 4.0-sec intervals, respectively.

\section{Discussion}

The main objective of Experiment 2 was to verify whether an effect of expectancy could be observed using a PI procedure with gaps, in trials where a gap is expected but does not occur. Peak times were shorter when the gap occurred later, as in Experiment 1, and more importantly, the shortest peak times were obtained in trials where participants were expecting a gap that did not occur. These results suggest that in the PI procedure, perceived time gradually decreased as duration of gap expectancy increased, independently of the gap occurrence: Shortest peak times were obtained in no-gap trials in which a gap

Table 6

Experiment 2: Means of Individual Start-Stop, Start-Spread, and Peak-Time-Spread Correlations at the Three Target Durations

\begin{tabular}{lrrr}
\hline & \multicolumn{3}{c}{ Target Duration $(\mathrm{sec})$} \\
\cline { 2 - 4 } & 2.4 & 3.2 & \multicolumn{1}{c}{4.0} \\
\hline Start-stop & .903 & .918 & .905 \\
Start-spread & .024 & -.039 & -.020 \\
Peak-time-spread & .185 & .117 & .155 \\
\hline
\end{tabular}


was expected throughout the time interval to be encoded. Whereas in Experiment 1, the effect of gap location on peak times was stronger at the shortest value of gap duration, there was no such interaction in Experiment 2, the effect of gap location being significant and equivalent at the two values of gap duration.

Peak times lengthened with increasing target durations, showing correct task execution. In contrast with Experiment 1 , peak times were affected neither by gap duration nor by any interaction between gap duration and other factors. One factor that may explain the difference is that values of gap duration were not identical in the two experiments of the present study ( 1 and $2 \mathrm{sec}$ in Experiment 1; 2 and $3 \mathrm{sec}$ in Experiment 2). In time discrimination with gaps, when an interval with gap was encoded and then classified as being short or long (Fortin \& Tremblay, 2006; Tremblay \& Fortin, 2003), no effect of varying gap duration was found, in contrast with results in time reproduction (Fortin et al., 2005). In the PI procedure, as in time discrimination, the gap is located during the encoding of the presented interval; under these conditions, the effect of varying gap duration seems much weaker and perhaps more sensitive to small variations in its average value. In effect, the average gap duration was $1 \mathrm{sec}$ longer in Experiment 2 than in Experiment 1 in the present study.

As in Experiment 1, variability tended to be relatively lower as target duration increased, as shown by spread/ peak-time ratios and CVs of peak times, which both decreased with increasing target duration. The relatively high value of spread/peak-time ratio in no-gap trials at the shortest target duration suggests that longer duration of expectancy might add variability to the memory representation, especially at short target durations. Absolute spread values did not increase with longer target durations in the present experiment. This might be expected given the relatively low range of target durations used in the present study, although the same range was large enough to reveal a significant effect of target durations on spreads in Experiment 1. A possibility is that in Experiment 2 , mixing trials with no gaps and trials with gaps made participants especially cautious about their stability in duration reproduction. Indeed, values of spreads were generally lower in Experiment 2 than in Experiment 1 ( 0.80 vs. 0.97 , on average).

Correlation coefficients suggest that as in Experiment 1 , the contribution of memory processes to performance was strong, whereas the contribution of response threshold processes was negligible.

\section{GENERAL DISCUSSION}

The objective of the present study was to test whether effects related to manipulating gap location, observed in previous studies when participants were reproducing (e.g., Fortin \& Massé, 2000) or discriminating (e.g., Tremblay $\&$ Fortin, 2003) time intervals, could be observed using a PI procedure. The results show that the PI procedure with humans is sensitive to effects of varying gap location; peak times of response distributions were shorter when the gap occurred later during the encoded target in- terval. When trials with no gaps with trials and gaps were mixed, peak times were even shorter than in trials with gaps. The last result supports strongly an interpretation of effects related to gap location in terms of expectancy; the shortening of peak times was roughly proportional to the duration for which the gap was expected. This finding confirms that the PI procedure may be used as evidence of effects related to expectancy in human timing. In the present study, results in trials with gaps and those without suggest that expecting a gap in the PI task shortened the encoded time and, correspondingly, reduced variability in response production in Experiment 1.

As in previous studies, the shortening of perceived duration with increasing duration of gap expectancy may be interpreted within an accumulation framework common to attentional models of time estimation (Brown, 1997; Zakay \& Block, 1996) and to SET (Gibbon, 1977; Gibbon et al., 1984). Assuming that interval timing relies on an accumulation process that requires attention, attention sharing between timing and monitoring for the gap signal would perturb this process (Fortin \& Massé, 2000; see also Casini \& Macar, 1997). This would in turn induce some loss in pulse accumulation, thereby shortening perceived duration. In the present study, this shortening was revealed in shorter peak times as the duration of gap expectancy increased.

A similar interpretation was offered to interpret results in animal timing (Lejeune, Macar, \& Zakay, 1999). In that study, pigeons were tested in a dual task involving duration discrimination and a variable ratio (VR) task reinforcing variable numbers of responses (the nontemporal task). The VR task could be positioned early or late during the signal to be timed. The percentage of "long" responses was lower in late than in early trials, suggesting temporal underestimation related to the duration preceding the VR task. The authors interpreted this finding within an internal clock model in which attentional shifts operating at the switch level before the occurrence of the VR task slowed down the rate of accumulating temporal information. This interpretation is clearly related to the hypothesis put forward to account for the effects of manipulating gap location in the present study. As noted by Lejeune et al., comparable findings in animal and in human timing studies suggest that similar mechanisms may underlie timing performance in humans and other animals (see also Allan, 1998; Penney et al., 2008). One must be cautious, however, in comparing the results of human and animal timing studies, in part because of notable differences in procedures. In the particular case of the PI procedure, values of gap durations and of target durations are typically much longer in animal than in human studies. In the present study, the target duration also changed from trial to trial, posing specific demands in working memory, whereas this duration is constant throughout experimental sessions in most animal experiments. Comparing human and animal timing studies may also be hazardous because the equivalence of attentional processes in humans and animals is debatable (Lejeune et al., 1999).

A gap location manipulation with pigeons also led to shifts in peak times directly related to the temporal loca- 
tion of a gap (Aum, Brown, \& Hemmes, 2004; Cabeza de Vaca et al., 1994). In an internal clock model, a number of mechanisms may mediate the shifts. For example, during an interval to be timed, a gap may interrupt timing, which is resumed at the end of the gap. This should shift the peak response curve rightward by approximately the length of the gap, implying that a "stop rule" is controlling temporal behavior (e.g., Meck, Church, \& Olton, 1984). Alternatively, peak time may be shifted to the right by a duration corresponding to the sum of the pregap and gap durations, indicating a reset rule, according to which timing is restarted from the beginning after the gap. Also according to a reset rule, pulses accumulated during the pregap period and stored in short-term memory are lost during the gap. Results intermediate between those predicted by a stop and a reset rule are predicted if accumulated temporal information decays in memory during the gap (e.g., Cabeza de Vaca et al., 1994). The rate of decay could be influenced by the degree of perceived salience of the gap, salience being defined as the degree to which the gap is discriminable from the interval to be timed (Buhusi, 2003). This hypothesis was supported in a PI study with rats, in which the intensity of the visual stimulus defining the gap was manipulated (Buhusi \& Meck, 2005). The authors concluded that accumulated time, during a gap, decays with a variable rate controlled by nontemporal parameters of the gap procedure, possibly through a mechanism involving attention sharing. Obviously, however, memory decay during the gap cannot account for the results with humans in the present study, since the strongest shifts in peak times were obtained in no-gap trials in Experiment 2.

When all trials included gaps in Experiment 1, peak times tended to be longer when the gap was longer, and within-trial variability increased correspondingly. This may suggest that, in a similar fashion to producing a welllearned time interval (Fortin et al., 2005), longer gaps could permit better preparation than shorter ones would to resume timing immediately after the gap. However, the effect of gap duration was marginal in Experiment 1 and was not obtained in Experiment 2. Varying gap duration seems therefore to produce weaker and less consistent results when the gap is located during the encoding phase of a timing task, which was also noted in a time discrimination paradigm (Tremblay \& Fortin, 2003).

Peak times were positively related to target durations, showing that the presented intervals were well discriminated. However, there was a regression toward the mean, so that when the shortest and longest target intervals were presented peak times tended to migrate toward $3.2 \mathrm{sec}$, the average target duration. This "migration" effect, which may be related to memory processes (e.g., Malapani, Deweer, \& Gibbon, 2002; Malapani \& Rakitin, 2003; Malapani et al., 1998) is sometimes observed when more than two target durations have to be estimated within the same experimental session and refers to Vierordt's law (see Brown, 1995). Another plausible interpretation refers to sensitivity to duration in timing tasks with and without concurrent processing requirements. A previous study showed that timing performance conformed more strongly to Vierordt's law when a second task was executed concurrently with timing than in a single timing task condition (Hemmes et al., 2004). In the same way, the gap manipulation in the present study may impose additional demands equivalent to those under dual-task conditions, inducing a regression of temporal estimates toward the mean.

Spreads of response distributions were positively related to peak times in Experiment 1; variability increased as the memory representation of target duration increased, an outcome to be expected, given Weber's law and the scalar property (Gibbon et al., 1984). However, variability was not strictly proportional to remembered time, but tended instead to be relatively lower as target duration increased, as shown, with spread/peak-time ratios and $\mathrm{CV}$ of peak times, both of which decreased with increasing target duration. Identical results were obtained with the start-stop procedure (Kladopoulos et al., 1998) and were also observed with the PI procedure (Rakitin et al., 1998). In the PI procedure, the time needed to execute the minimum number of responses is relatively shorter at longer target durations, which may lead to relatively lower variability. Besides, this pattern is not atypical with human participants (Killeen \& Weiss, 1987), and might come from some contribution of chronometric counting in human temporal performance, with intercount intervals that may be scaled according to the scalar property (Wearden, 1991). Note that the objective of the present study was not to verify the scalar property in humans; in that case, wider ranges of target durations would have been required. In Experiment 2, there was no obvious relationship between variability and target durations within the range of temporal values investigated. Even though differences in spreads were obtained in Experiment 1 with similar time estimates, significant differences in variability may sometimes be difficult to detect with such a small range of perceived durations.

Finally, correlations between start and stop times as well as of peak times and spreads suggested a strong contribution of memory processes in the present study. Although correlations between start times and spreads were negative at most target durations (see Tables 3 and 6), they were closer to zero than in previous human studies using similar intervals with feedback (e.g., Kladopoulos et al., 1998, Experiment 2). Nevertheless, correlations did not vary with duration of gap expectancy or of the gap itself, showing that neither expecting an interruption nor interrupting timing affected the relative contributions of memory and response threshold processes.

To conclude, the present study revealed some similarities and some differences in timing performance in humans and other animals. The similarities concern some basic features of temporal performance in the PI procedure, as well as a possible influence of cognitive factors, such as expectancy and attention on timing mechanisms. The results of the present study, together with those obtained in animal timing studies (e.g., Aum et al., 2004; Buhusi \& Meck, 2006a, 2006b; Lejeune et al., 1999; Penney et al., 2008), may contribute to the development of an integrated view of timing in humans and other animals. 


\section{AUTHOR NOTE}

This work was supported by a grant from the Natural Sciences and Engineering Research Council of Canada (NSERC) to C.F. We thank Nancy Bélanger for her help in data collection, and Claude Perreault for useful comments on a previous version. Correspondence concerning this article should be addressed to C. Fortin, École de psychologie, Université Laval, Québec, QC, G1V 0A6 Canada (e-mail: claudette .fortin@psy.ulaval.ca).

\section{REFERENCES}

Allan, L. G. (1998). The influence of the scalar timing model on human timing research. Behavioural Processes, 44, 101-117.

Aum, S. W., Brown, B. L., \& Hemmes, N. S. (2004). The effects of concurrent task and gap events on peak time in the peak procedure. Behavioural Processes, 65, 43-56.

Brown, S. W. (1995). Time, change, and motion: The effects of stimulus movement on temporal perception. Perception \& Psychophysics, 57, 105-116.

BRown, S. W. (1997). Attentional resources in timing: Interference effects in concurrent temporal and nontemporal working memory tasks. Perception \& Psychophysics, 59, 1118-1140.

BuHusi, C. V. (2003). Dopaminergic mechanisms of interval timing and attention. In W. H. Meck (Ed.), Functional and neural mechanisms of interval timing (pp. 317-338). Boca Raton, FL: CRC Press.

Bunusi, C. V., \& Meck, W. H. (2000). Timing for the absence of a stimulus: The gap paradigm reversed. Journal of Experimental Psychology: Animal Behavior Processes, 26, 305-322.

Bunusi, C. V., \& Meck, W. H. (2002). Differential effects of methamphetamine and haloperidol on the control of an internal clock. Behavioral Neuroscience, 116, 291-297.

Bunusi, C. V., \& Meck, W. H. (2005). What makes us tick? Functional and neural mechanisms of interval timing. Nature Reviews Neuroscience, 6, 755-765.

Buhusi, C. V., \& Meck, W. H. (2006a). Interval timing with gaps and distracters: Evaluation of the ambiguity, switch, and time-sharing hypotheses. Journal of Experimental Psychology: Animal Behavior Processes, 32, 329-338.

Buhusi, C. V., \& Meck, W. H. (2006b). Time sharing in rats: A peakinterval procedure with gaps and distracters. Behavioural Processes, 71, 107-115.

Buhusi, C. V., \& Meck, W. H. (2007). Effect of clozapine on interval timing and working memory for time in the peak-interval procedure with gaps. Behavioural Processes, 74, 159-167.

Buhusi, C. V., Perera, D., \& Meck, W. H. (2005). Memory for timing visual and auditory signals in albino and pigmented rats. Journal of Experimental Psychology: Animal Behavior Processes, 31, 18-30.

Buhusi, C. V., SASAKI, A., \& MECK, W. H. (2002). Temporal integration as a function of signal and gap intensity in rats (Rattus norvegicus) and pigeons (Columba livia). Journal of Comparative Psychology, 116, 381-390.

Cabeza de Vaca, S., Brown, B. L., \& Hemmes, N. S. (1994). Internal clock and memory processes in animal timing. Journal of Experimental Psychology: Animal Behavior Processes, 20, 184-198.

CASINI, L., \& MACAR, F. (1997). Effects of attention manipulation on judgments of duration and of intensity in the visual modality. Memory \& Cognition, 25, 812-818.

Cheng, K., \& Miceli, P. (1996). Modelling timing performance on the peak procedure. Behavioural Processes, 37, 137-156.

Cheng, K., \& Westwood, R. (1993). Analysis of single trials in pigeons' timing performance. Journal of Experimental Psychology: Animal Behavior Processes, 19, 56-67.

Church, R. M., Meck, W. H., \& Gibbon, J. (1994). Application of scalar timing theory to individual trials. Journal of Experimental Psychology: Animal Behavior Processes, 20, 135-155.

ForTIN, C. (2003). Attentional time-sharing in interval timing. In W. H. Meck (Ed.), Functional and neural mechanisms of interval timing (pp. 235-260). Boca Raton, FL: CRC Press.

Fortin, C., BÉdard, M.-C., \& Champagne, J. (2005). Timing during interruptions in timing. Journal of Experimental Psychology: Human Perception \& Performance, 31, 276-288.

Fortin, C., \& MAsSÉ, N. (2000). Expecting a break in time estimation:
Attentional time-sharing without concurrent processing. Journal of Experimental Psychology: Human Perception \& Performance, 26, 1788-1796.

Fortin, C., \& Tremblay, S. (2006). Interrupting timing in interval production and discrimination: Similarities and differences. Behavioural Processes, 71, 336-343.

GibBon, J. (1977). Scalar expectancy theory and Weber's law in animal timing. Psychological Review, 84, 279-325.

Gibbon, J., \& Church, R. M. (1990). Representation of time. Cognition, 37, 23-54.

Gibbon, J., Church, R. M., \& Meck, W. H. (1984). Scalar timing in memory. In J. Gibbon \& L. G. Allan (Eds.), Timing and time perception (Annals of the New York Academy of Sciences, Vol. 423, pp. 5277). New York: New York Academy of Sciences.

Gibbon, J., Malapani, C., Dale, C. L., \& Gallistel, C. R. (1997). Toward a neurobiology of temporal cognition: Advances and challenges. Current Opinion in Neurobiology, 7, 170-184.

Hemmes, N. S., Brown, B. L., \& Kladopoulos, C. N. (2004). Time perception with and without a concurrent nontemporal task. Perception \& Psychophysics, 66, 328-341.

Hinton, S. C., \& MEcK, W. H. (2004). Frontal-striatal circuitry activated by human peak-interval timing in the supra-seconds range. Cognitive Brain Research, 21, 171-182.

Killeen, P. R., \& Weiss, N. A. (1987). Optimal timing and the Weber function. Psychological Review, 94, 455-468.

Kladopoulos, C. N., Brown, B. L., Hemmes, N., S., \& Cabeza de VACA, S. (1998). The start-stop procedure: Estimation of temporal intervals by human subjects. Perception \& Psychophysics, 60, 438-450.

Lejeune, H., Macar, F., \& ZaKaY, D. (1999). Attention and timing: Dualtask performance in pigeons. Behavioural Processes, 45, 141-157.

Lustig, C., \& Meck, W. H. (2005). Chronic treatment with haloperidol induces deficits in working memory and feedback effects of interval timing. Brain \& Cognition, 58, 9-16.

MACAR, F. (2002). Expectancy, controlled attention and automatic attention in prospective temporal judgments. Acta Psychologica, 111, 243-262.

MacDonald, C. J., \& MecK, W. H. (2004). Systems-level integration of interval timing and reaction time. Neuroscience \& Biobehavioral Reviews, 28, 747-769.

Malapani, C., Deweer, B., \& Gibbon, J. (2002). Separating storage from retrieval dysfunction of temporal memory in Parkinson's disease. Journal of Cognitive Neuroscience, 14, 311-322.

MaLAPANI, C., \& RAKITIN, B. C. (2003). Interval timing in the dopaminedepleted basal ganglia: From empirical data to timing theory. In W. H. Meck (Ed.), Functional and neural mechanisms of interval timing (pp. 485-514). Boca Raton, FL: CRC Press.

Malapani, C., Rakitin, B. [C.], Levy, R., Meck, W. H., Deweer, B., Dubors, B., \& GibBon, J. (1998). Coupled temporal memories in Parkinson's disease: A dopamine-related dysfunction. Journal of Cognitive Neuroscience, 10, 316-331.

Matell, M. S., Bateson, M., \& Meck, W. H. (2006). Single-trials analyses demonstrate that increases in clock speed contribute to the methamphetamine-induced horizontal shifts in peak-interval timing functions. Psychopharmacology, 188, 201-212.

Meck, W. H., Church, R. M., \& Olton, D. S. (1984). Hippocampus, time, and memory. Behavioral Neuroscience, 98, 3-22.

Penney, T. B., GibBon, J., \& Meck, W. H. (2008). Categorical scaling of duration bisection in pigeons (Columba livia), mice (Mus musculus), and humans (Homo sapiens). Psychological Science, 19, 1103-1109.

Rakitin, B. C., Gibbon, J., Penney, T. B., Malapani, C., Hinton, S. C., \& MecK, W. H. (1998). Scalar expectancy theory and peakinterval timing in humans. Journal of Experimental Psychology: Animal Behavior Processes, 24, 15-33.

Tremblay, S., \& Fortin, C. (2003). Break expectancy in duration discrimination. Journal of Experimental Psychology: Human Perception \& Performance, 29, 823-831.

Wearden, J. H. (1991). Do humans possess an internal clock with scalar timing properties? Learning \& Motivation, 22, 59-83.

ZAKAY, D. (2000). Gating or switching? Gating is a better model of prospective timing (a response to "switching or gating?" by Lejeune). Behavioural Processes, 52, 63-69.

ZAKAY, D., \& BLOCK, R. A. (1996). The role of attention in time estimation processes. In M. A. Pastor \& J. Artieda (Eds.), Time, internal clocks and movement (pp. 143-163). Amsterdam: Elsevier. 


\section{APPENDIX A}

Experiment 1

Results of ANOVAs on Start-Stop, Start-Spread, and Peak-Time-Spread Correlations

\begin{tabular}{lrccc}
\hline & & \multicolumn{3}{c}{$F$ Values and Mean Square Errors } \\
\cline { 3 - 5 } \multicolumn{1}{c}{ Source } & $d f$ & Start-Stop & Start-Spread & Peak-Time-Spread \\
\hline Target duration (TD) & 2 & 0.108 & 2.253 & 1.619 \\
Error & 30 & 0.020 & 0.016 & 0.218 \\
Gap location (GL) & 1 & 0.052 & 1.226 & 1.111 \\
Error & 15 & 0.040 & 0.269 & 0.256 \\
Gap duration (GD) & 1 & 1.100 & 0.001 & 0.418 \\
Error & 15 & 0.032 & 0.135 & 0.169 \\
TD $\times$ GL & 2 & 0.851 & 0.024 & 0.220 \\
Error & 30 & 0.051 & 0.217 & 0.188 \\
TD $\times$ GD & 2 & 1.494 & 2.308 & 2.968 \\
Error & 30 & 0.034 & 0.168 & 0.169 \\
GL $\times$ GD & 1 & 0.428 & 0.734 & 0.707 \\
Error & 15 & 0.044 & 0.271 & 0.223 \\
TD $\times$ GL $\times$ GD & 2 & 1.289 & 1.829 & 1.138 \\
Error & 30 & 0.034 & 0.241 & 0.212 \\
\hline N & &
\end{tabular}

Note-All $F$ s nonsignificant at $\alpha=.05$.

APPENDIX B

Experiment 2

Results of ANOVAs on Start-Stop, Start-Spread, and Peak-Time-Spread Correlations

\begin{tabular}{lrccc}
\hline & & \multicolumn{3}{c}{$F$ Values and Mean Square Errors } \\
\cline { 3 - 5 } \multicolumn{1}{c}{ Source } & $d f$ & Start-Stop & Start-Spread & Peak-Time-Spread \\
\hline Target duration (TD) & 2 & 0.537 & 0.398 & 0.405 \\
Error & 28 & 0.005 & 0.117 & 0.131 \\
Gap location (GL) & 2 & 0.116 & 0.013 & 0.058 \\
Error & 28 & 0.015 & 0.134 & 0.131 \\
TD $\times$ GL & 4 & 0.663 & 0.213 & 0.270 \\
Error & 56 & 0.009 & 0.174 & 0.168 \\
\hline
\end{tabular}

(Manuscript received February 26, 2008;

revision accepted for publication December 2, 2008.) 